\title{
A first satellite-based observational assessment of urban thermal anisotropy
}

\author{
Leiqiu $\mathrm{Hu}^{\mathrm{a}, *}$, Andrew Monaghan ${ }^{\mathrm{a}}$, James A. Voogt ${ }^{\mathrm{b}}$, Michael Barlage ${ }^{\mathrm{a}}$ \\ ${ }^{a}$ National Center for Atmospheric Research, Boulder, CO, USA 80307 \\ ${ }^{b}$ Department of Geography, University of Western Ontario, London, ON, Canada N6A \\ 5C2
}

\section{Abstract}

Complex urban environments with diverse urban canyon structures and building materials mixed with human-modified green space substantially influence the directional variation in upwelling thermal radiance. The thermal anisotropy at a satellite pixel scale (e.g. $1 \mathrm{~km})$ is hard to quantify with current techniques through airborne observations and modeling. The various anisotropic features over urban and rural surfaces lead to an uncertainty regarding how this anisotropy of land surface temperature (LST) influences estimates of the surface urban heat island (SUHI). We quantify LST anisotropy over Chicago and New York using MODIS LST products during the warm months (May-September) for a 10-year period. The impacts of atmospheric attenuation and daily weather variability on LST are removed in order to isolate the anisotropic signal. We then calculate the anisotropy for different levels of urban land use intensity. The daytime maximum anisotropic effects can be up to $9 \mathrm{~K}$ for the most urbanized areas, while the nighttime

*leiqiu@ucar.edu

Preprint submitted to Remote Sensing of Environment

March 19, 2016

(C) 2016. This manuscript version is made available under the Elsevier user license http://www.elsevier.com/open-access/userlicense/1.0/ 
anisotropic effects are weaker but still discernible. Two anisotropic "hot spot" features are observed during daytime: one corresponds to the sensorsun geometric effect with a higher proportion of sunlit surface components been seen a given view configuration, and the other occurs when sensor zenith angles are near nadir in the afternoon. Similar anisotropic features between the two cities confirm the broader applicability of our approach, while some unique features specific to each city emphasize that diverse urban surface properties and geographic settings can affect anisotropy. This study is the first of its kind to directly evaluate the influence of directional anisotropy on satellite-retrieved SUHI measurements, demonstrating that anisotropic effects can possibly modify the SUHI as measured with MODIS LST by $2.3 \mathrm{~K}$, which is about $25 \sim 50 \%$ of the total magnitude of the SUHI over Chicago and New York. Our findings provide a statistical basis for the quantification of satellite-retrieved LST anisotropy over heterogeneous urban environments globally.

Keywords: Satellite thermal remote sensing, thermal anisotropy, land surface temperature, MODIS, surface urban heat island

\section{Introduction}

2 Land surface temperature (LST) is an important indicator of surface en3 ergy and moisture conditions (Li et al., 2013). LSTs retrieved from satellite 4 data provide a means to understand land surface processes efficiently via 5 consistent periodicity, high-spatial resolution, and global coverage. Satellite- 
retrieved LST has been widely applied to investigate soil moisture, surface energy fluxes, surface hydrology, vegetation dynamics, and environmental and ecological changes (Zhang et al., 2015; Voogt and Grimmond, 2000; Voogt and Oke, 2003; Weng et al., 2004, 2014; Rigo and Parlow, 2007). For urban climate research, satellite-based LST has the ability to comprehensively depict the complex temperature distribution spatially in highly heterogeneous urban environments. Satellite-based LST measurements can compensate for or complement traditional intra-urban measurements from ground-based observations, which often have limited footprints and relatively sparse coverage across urban regions, or are only installed for a short period during intensive urban field campaigns. Consequently, satellite-based LST fields have been widely used for surface urban heat island (SUHI) studies (Voogt and Oke, 2003; Hung et al., 2006; Schwarz and Manceur, 2014), and also have been assimilated into urban land/atmosphere model simulations or used to validate them (Li and Bou-Zeid, 2013; Monaghan et al., 2014).

However, the anisotropy of satellite-based LST measurements is widely found over a variety of surfaces including vegetated (Kimes, 1980; Pinheiro et al., 2004), bare soil (Sobrino and Cuenca, 1999; Cuenca and Sobrino, 2004), and urban areas (Lagouarde et al., 2004; Lagouarde and Irvine, 2008; Lagouarde et al., 2012), which means the LST varies depending on the sensor view direction. The anisotropy of LST primarily results from the angular variation of nonisothermal components and emissivity detected from an instantaneous field of view (IFOV) (Li et al., 2013). The three-dimensional (3D) structure of 
the surface creates temperature variability due in part to different local solar zenith and azimuth angles on facets that create anisotropy (Lagouarde et al., 2000; Voogt, 2008; Duffour et al., 2015). The anisotropy is generated from the biased view of the facets that make up the urban surface from a particular view direction (Kimes, 1980; Lagouarde et al., 2004; Lagouarde and Irvine, 2008; Lagouarde et al., 2014; Duffour et al., 2015; Krayenhoff and Voogt, 2016). There are also other influences on anisotropy such as biases in material properties with orientations that may contribute to surface temperature differences. Thus, in complex urban environments with diverse urban canyon structures and building materials, mixed with human-modified green space, there is a particularly strong influence on the anisotropy of satellite-based LST (Voogt, 2008).

Previous studies have demonstrated a substantial contrast between daytime and nighttime anisotropic patterns. The anisotropic LST can exceed $10 \mathrm{~K}$ during the daytime over highly urbanized districts (Lagouarde et al., 2004; Lagouarde and Irvine, 2008; Voogt, 2008). The daytime anisotropic pattern reveals a significant "hot-spot" effect (a local maximum in the nearfull hemispheric distribution of radiative temperature), where the sensor views the maximum proportions of sunlit components (the Sun is behind the sensor as it views the surface object). Anisotropy decreases rapidly following sunset so that it becomes small and nearly azimuthally independent later in the evening (Lagouarde et al., 2012).

Currently, direct observations from airborne sensors complimented with 
in-situ measurements, and sensor-viewing modeling, are two primary approaches to assess the effects of anisotropy on LST (or brightness temperature) measurement in urban environments (Lagouarde et al., 2004; Lagouarde and Irvine, 2008; Voogt, 2008). Integrated observations and modeling can help to establish a relatively comprehensive quasi-simultaneous LST anisotropy distribution, which may help minimize anisotropic effects on satellite-based LST measurements. However, there are a number of issues associated with applying airborne and modeling approaches to adjust for the anisotropy of urban LST measurements from satellites. First, the validity of upscaling the fine scale experiments to comparatively coarse resolution satellite-based LST is uncertain (e.g. Moderate Resolution Imaging Spectroradiometer (MODIS) has $1 \mathrm{~km}$ resolution). For example, it isn't clear how much impact of surface topography variation and spatial variations of urban surface structures (e.g. built and vegetated structure and arrangements) at a fine scale affect the anisotropy at satellite observational scale. Moreover, we have limited information on facet-scale variations of emissivity, and almost no information on whether individual material has emissivity that is non-isotropic. Second, airborne observations are quite expensive to obtain, which make it impossible to conduct experiments over various types of cities globally. Third, the impact of anisotropic LST on SUHI quantifications is unknown due to the possible dissimilar anisotropic features of LST over urban and rural areas.

Anisotropy can be a particularly acute problem for sensors aboard polarorbiting satellites designed to take repeat images with high temporal fre- 
quency, because they have wide fields of view and a broad range of sensor zenith angles (ZA) in the cross track direction (Li et al., 2013). MODIS and Advanced Very High Resolution Radiometer (AVHRR) are infrared sensors that fall into this category. For instance, the sensor ZA of MODIS can be up to $65^{\circ}$ in the cross-track direction. Due to anisotropy, LST detected from different sensor positions can confound the quantification of SUHI intensity, leading to unreliable estimates of SUHI over short timescales, such as daily. Moreover, additional biases can be introduced in studies that empirically correlate satellite-based LST and in-situ or gridded air temperature records regionally or globally.

Currently, substantial efforts are required to fully characterize and adjust for the anisotropic LST from satellites for urban applications. The challenges arise for a number of reasons. First, many factors that control anisotropic features of LST vary at multiple temporal and spatial scales: e.g., the annual solar angle change, vegetation phenology, weather variability, the urban built form as well as its relation to vegetation. Additionally, spatial variations in material properties may impact anisotropy, either due to differences in construction of different types of buildings in a particular city or due to differences in construction practices globally. Second, atmospheric effects are partially determined by the distance between the target and sensor, which is a function of the highly-variable sensor viewing angle. Unfortunately, completely eliminating the atmospheric impact on LST retrievals remains challenging for the foreseeable future (Li et al., 2013). Third, little 
is known about the influence on LST of vegetation anisotropy within urban areas (Dyce, 2014), though most city environments have abundant vegetation that is difficult to distinguish from built-up components at the satellite observational scale. Vegetation types and coverage vary extensively across urban areas and thus are difficult and expensive to measure. In summary, it is demanding to measure and account for these fine scale effects at the satellite pixel scale over urban regions.

This study uses a novel method to assess the anisotropy of MODIS LST measurements over long-time scales (multi-year seasonal averages). The approach includes strategies to separate the influence of the atmosphere (after the atmospheric correction) and the influence of variable weather conditions from LST products. Our primary objectives are to quantify LST anisotropic features over various urban environments, estimate the SUHI variations due to the anisotropic LST, and demonstrate the applicability of our methodology for broader applications.

\section{Data and Methodology}

\subsection{Study Areas and Data}

Two large U.S. cities and their surrounding metropolitan areas are chosen for the experiment. Chicago is located on the southwestern shore of Lake Michigan with a population of about 2 million residents in the city and about 9.5 million in the metropolitan area (U.S. Census Bureau Population Division, 2014). This city has a humid continental climate with warm-to-hot and hu- 

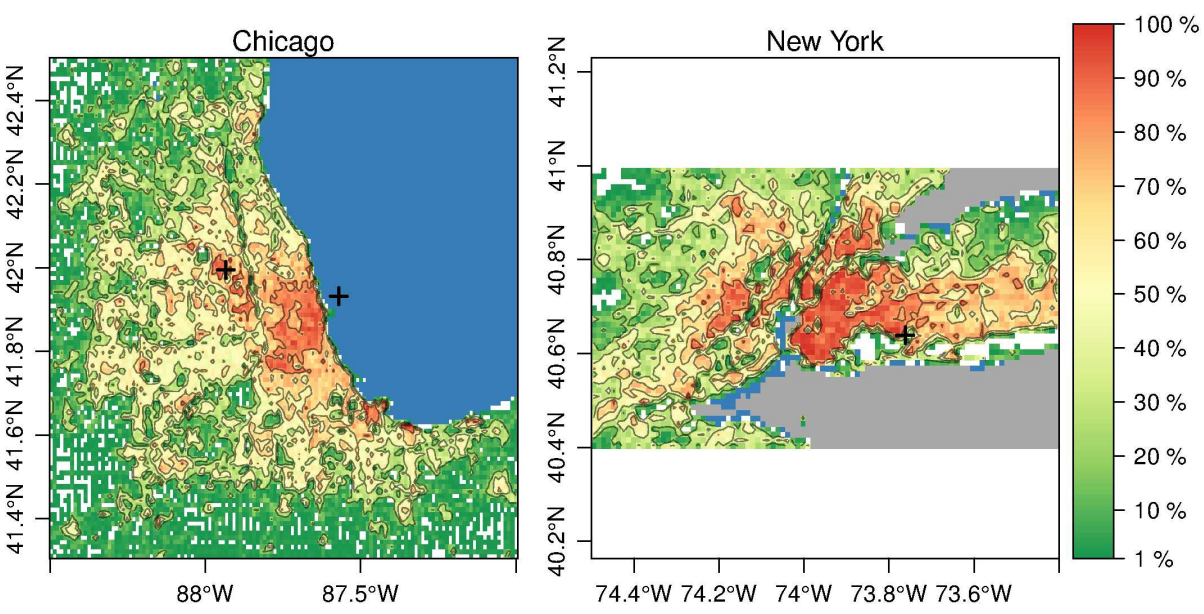

Figure 1: The urban land use fraction at $1 \mathrm{~km}$ resolution for Chicago $(181 \mathrm{~km}$ by $181 \mathrm{~km})$ and New York City $(85 \mathrm{~km}$ by $145 \mathrm{~km})$. The black contours separate the urban land use fraction at $20 \%, 40 \%, 60 \%$ and $80 \%$. The regions in white and blue in the domains represent non-urban area and pure water surfaces, respectively. The grey area in New York City indicates where MODIS LST data are unavailable. The cross symbols show the locations of meteorological weather stations over the land and water surfaces; the weather station over the water surface for New York (not shown) is outside the domain.

mid summers. New York City has a population of about 8.5 million in the city and about 19.5 million in the metropolitan area (U.S. Census Bureau Population Division, 2014), which is located in the northeastern U.S. coastal area under the influence of the Atlantic Ocean. The city experiences a humid subtropical climate based on Koppen-Geiger climate classification (Kottek et al., 2006) with warm-to-hot and humid summers. The study domains used for the statistical analyses for each city are shown in Fig. 1. In order to produce representative and robust results, a large sample size of both urban areas and pure water surfaces is required. Therefore, extended regions were used for the initial data processing. Additional details are discussed in Section 2.2. 
MODIS is onboard NASA's Terra and Aqua polar-orbiting satellites, which pass over the same location on Earth once or twice per day. Compared to the temporal flexibility of aircraft measurements, satellite orbits are predesigned and shifted slightly for each revolution of the Earth. Consequently, the sun-surface-sensor geometry and overpass time for a given location vary daily. The sensor and solar zenith angles (ZA) (and azimuthal angles (AA)) used in this study take the surface targets as references, which are defined as the angles from the nadir of a given grid cell to the sensor or Sun line of sight (see Fig.2(a)). The sensor ZA is defined as the angle between the satellite sensor and nadir, shown as the shaded blue angle in Fig.2 (a). The sensor AAs (i.e. the surface object to the sensor with respect to north in a clockwise direction, indicated by the blue arrow in Fig.2(a)) of satellite observations are nearly perpendicular to the axes of the track direction, and are approximately easterly or westerly depending on which side of the city the track for a given overpass occurs (see Fig. 2 (b) and (c) for Chicago). To simplify the notation in the later analysis, we use the positive and negative ZA to indicate whether the sensor/solar azimuthal angle is smaller than $180^{\circ}$ (close to easterly) or larger than $180^{\circ}$ (close to westerly). The observations from MODIS have a large range of sensor ZAs up to $+/-65^{\circ}$ due to a scan angle of up to $55^{\circ}$ and a wide swath of coverage for each satellite overpass. The sensor zenith and azimuth angle distributions of LST in Chicago for day and night are shown in Fig. 2 (b) and (c), respectively.

In contrast to airborne measurements or model simulations of quasi- 


\section{(a) Sensor Angles}
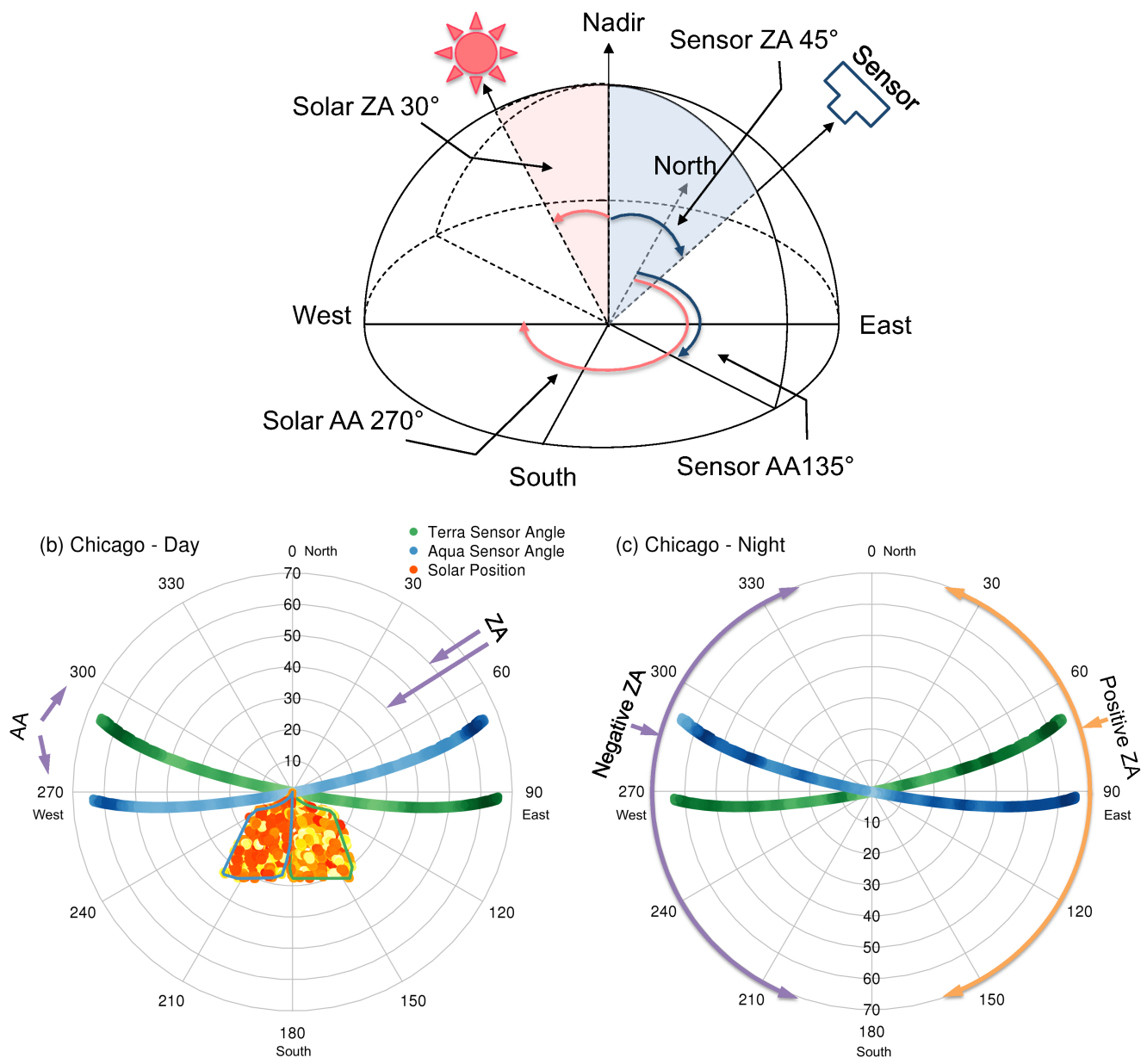

Figure 2: (a) The definition of the sensor/Sun zenith angle (ZA) and sensor azimuth angles (AA) in this study, where the surface object is the reference and the angles are measured from surface objects to the sensor/Sun indicated as blue and red arrows in the figure, respectively. (b) and (c) are polar plots of the sensor angle distributions and corresponding solar positions of cloud-free LST measurements in the Chicago area during daytime and nighttime, respectively. The polar plots show the surface to the sensor/Sun AA for the radii $\left(0-360^{\circ}\right)$ and $\mathrm{ZA}$ for the circles $\left(0-65^{\circ}\right)$. The green color represents data from the Terra satellite, where the distribution range of corresponding solar positions for Terra observations are defined by the polygon in green (The yellow-to-red colors within the polygon indicate the frequency (high-to-low) of solar positions). Aqua is similarly illustrated in blue. A higher frequency of surface-sensor geometric positions has a darker color. The distribution for New York is similar (not shown). The positive and negative ZAs described in (c), a notation that is used for simplification in the later analysis, represent the surface-sensor azimuth angles that are smaller (postive) and larger (negative) than $180^{\circ}$. 
simultaneous anisotropy, it is difficult to obtain multi-angular satellite observations simultaneously of the same ground object (Ren et al., 2015). The angular LST analyses in this study thus represents a long-term, metropolitanscale statistical viewpoint. Moreover, here we use LST rather than brightness temperature (which is widely used in airborne observations for anisotropy studies), and thus the emissivity for the LST retrieval is estimated based on the land cover types (Snyder et al., 1998), so it does not account for the uncertainty of emissivity due to the view angle, "cavity" effects from the urban canyon, or the heterogeneous surface components within a pixel.

The MODIS Land Surface Temperature and Emissivity 5-minute Level 2 version 5 product (MOD11_L2 from Terra and MYD11_L2 from Aqua) is the primary data used for the anisotropic LST assessment. This LST product is produced daily at 5 -minute increments using the generalized splitwindow algorithm with a spatial resolution of approximately $1 \mathrm{~km}$ at nadir (Wan and Dozier, 1996; Wan, 2007). The corresponding sensor and solar ZA and AA for each LST pixel is extracted from the MODIS geolocation product (MOD03 from Terra and MYD03 from Aqua) at $1 \mathrm{~km}$ resolution. The median local solar time of four satellite overpasses is about 11:00 (Terra-Day),13:00 (Aqua-Day), 22:00 (Terra-Night), and 2:00 (Aqua-Night) for Chicago and New York City. We collected the daily MODIS LST/geolocation products from May to September during 2003-2012. Additionally, to reduce impacts from cloud contaminated pixels (e.g. cloud edges), the lowest LST threshold was set to $270 \mathrm{~K}$, and low-temperature outliers were removed (defined as a 
pixel with a temperature $<1.5$ times the interquartile range of the $25 \%$ LST distribution of pixels in each image). Finally, LST images with more than $75 \%$ of clear-sky coverage over land surfaces and at least $20 \%$ (Chicago) or $80 \%$ (New York) clear-sky pixels over pure water surfaces were selected for analysis.

We only assessed the five warmest months (May-September) of the year. The selected months provide a range of variations in the solar position (e.g. solar angle distributions for Chicago for Terra-Day and Aqua-Day in Fig. 2(b)), yet have relatively stable vegetation conditions over urban areas. Also, the warmer seasons avoid the effects of winter snow or frozen water surfaces, which may modulate the LST anisotropy in a manner that we cannot account for. It is also important to quantify the impact of anisotropy on SUHI when the negative effects of the UHI are most influential. Our approach is thus simple and reasonably representative.

In order to identify urban areas, water surfaces and vegetation cover with the highest fidelity possible, we employed the $30 \mathrm{~m}$ spatial resolution $2006 \mathrm{Na}-$ tional Land Cover Database (Homer et al., 2012)(http://www.mrlc.gov/nlcd06_data.php). To match the scale of MODIS LST, the original land cover data were spatially aggregated to $1 \mathrm{~km}$ by calculating land use type ratios in each $1 \mathrm{~km}$ grid cell. Ancillary data of building footprints with building height information were collected for Chicago (https://data.cityof chicago.org/) and New York City (https://data.cityofnewyork.us/). The spatial coverage of datasets is limited to the administrative boundary. We aggregated and characterized 
the urban morphology at the $1 \mathrm{~km}$ scale from building information to match the LST spatial resolution.

In each city, one pair of air temperatures from meteorological weather stations over land and water surfaces are used to decrease the impact of daily weather variation on anisotropy quantification (see locations of weather stations in Fig. 1, cross symbol). The hourly near-surface observations over land are from National Oceanographic and Atmospheric Administration (NOAA) National Centers for Environmental Information (NCEI), including sites from the John F. Kennedy International Airport (USAF-725053, New York) and Chicago O'Hare International Airport (USAF-725300, Chicago). Over water, a buoy $61 \mathrm{~km}$ south of Long Island (USAF-996420, near New York) is also from NOAA NCEI, and a site over Lake Michigan near Chicago is from the NOAA Great Lakes Environmental Research Laboratory (http://www.glerl .noaa.gov/metdata/ The observations are selected within $1 \mathrm{hr}$ of each satellite overpass during the study period and are quality-controlled.

\subsection{Methods}

Each LST pixel has an unique solar/sensor angle configuration in a satellite swath; meanwhile, the sensor ZA and AA variation at a city scale is relatively small in each swath. Consequently, in order to quantify angular variations of MODIS LST from sensor ZA $-65^{\circ}$ to $+65^{\circ}$ over heterogeneous urban surfaces, we have to minimize other possible anisotropic contributors, such as atmospheric attenuation, to decrease other impacts on quantifying 
the anisotropy, such as daily weather variation, and to carefully identify anisotropy from spatiotemporally integrated information. In this section, we introduce practical methods to isolate the anisotropic effects from MODIS LST products by subtracting different terms that could represent the biases from atmospheric effects and weather variability. The resultant dataset $\left(\Delta L S T_{\Delta T_{a i r}}\right)$ derived from LST is only a function of anisotropy (without a physical meaning). By quantifying the relative $\Delta L S T_{\Delta T_{a i r}}$ variation, we therefore are able to assess the anisotropy of LST due to different surface structure and properties in cities for each satellite overpass.

\subsubsection{Reducing the impact of angular atmospheric attenuation}

The anisotropic effect of LST products can directly come from both various surface properties as well as residual atmospheric effects in a certain view configuration. The calculation of MODIS LST at $1 \mathrm{~km}$ is based on a generalized split-window algorithm by Wan and Dozier (1996), which corrects for atmospheric effects based on the differential absorption in two thermal bands from MODIS, rather than directly relying on radiative transfer models and atmospheric profiles. Consequently, it is difficult to physically identify the sources of uncorrected atmospheric attenuation from the LST products. Therefore, we propose an indirect way to decrease the impact of possible angular atmospheric effects in LST products. First, we assume that atmospheric conditions are similar over adjacent land and water areas, so the impact of angular atmospheric attenuation over land pixels can then be 
approximately canceled by subtracting water surface temperature from land surface temperature for pixels with similar sensor ZAs, sensor azimuth angles, and observation times (within the same satellite image). We define the LST difference between land surfaces and pure-water surfaces by Eq. 1.

$$
\Delta L S T(t)=L S T(t)-\overline{L S T_{\text {water }}(t)}
$$

where $\mathrm{t}$ is the satellite overpass time when the LSTs are observed within 5 min, and $\overline{L S T_{\text {water }}(t)}$ is the averaged LST of all water pixels in the domain. In reality, this equation would also be a function of the sensor AAs and ZAs. However, the differences among sensor AAs in a given image are very small (about $2^{\circ}$ ), and can be neglected. While the sensor ZA spans a larger range of angles (up to $14^{\circ}$ for Chicago and $9^{\circ}$ in New York but often less), the geographic clustering of pure water pixels in each domain makes it impossible to calculate spatial-averaged $\overline{L S T_{\text {water }}}$ for the full range of sensor ZAs over land for most overpasses. Thus, we also neglect sensor ZA differences when solving Eq. 1.

The surface of deep and relatively calm water bodies has a near-isotropic surface temperature distribution due to its homogenous surface properties (Niclòs et al., 2004, 2005). Hence, $\Delta L S T$ does change the anisotropic information caused by land surface properties. In order to show the existence of atmospheric impact and the effectiveness of our proposed method, the $L S T_{\text {water }}$ and $\Delta L S T_{\text {water }}$ (LST and $\Delta L S T$ over pure water surfaces) distri- 
butions as a function of sensor ZA for Chicago and New York are shown in Fig. 3. Any directionality of the observed temperature over water is due to atmospheric attenuation, therefore the impacts of atmospheric attenuation are particularly pronounced during nighttime in New York, where increasing sensor ZAs are associated with decreasing LST (red lines, left $\mathrm{y}$-axis). The relatively even distributions of $\Delta L S T_{\text {water }}$ (blue lines, right y-axis) demonstrate that we can effectively minimize the possible angular effects from atmospheric attenuation on the MODIS LST product. The distribution of $\Delta L S T_{\text {water }}$ is consistent with our assumption that the water surface is near-Lambertian. The residual atmospheric impact might be surface temperature-dependent (e.g. the attenuation by the atmosphere from surface emission), or surface temperature-independent (e.g. the upwelling path radiance from atmosphere), so the simple subtraction of LST over land and adjacent water surfaces may not necessarily completely remove the residual impact from atmosphere over urban areas. Since the split-window algorithm does physically-consider atmospheric effects for LST retrievals, the residual atmospheric impact is relatively small and not necessarily constant across space and time (e.g. Fig. 3 for Chicago). The $\Delta L S T$ term will thus reduce the residual atmospheric effect if it exists in the product (e.g., Fig. 3 for New York at nighttime). 


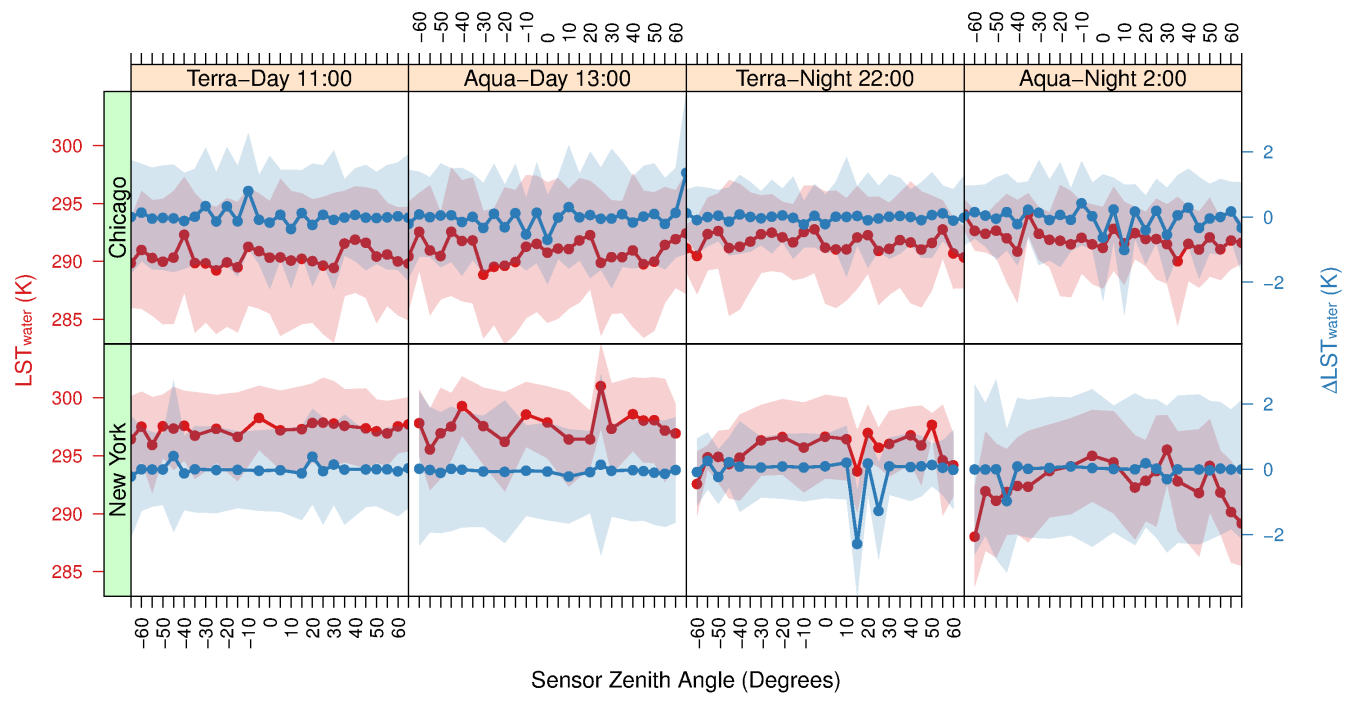

Figure 3: The distributions of LST ( $L S T_{\text {water }}$, left y-axis, red) and $\Delta L S T$ ( $\Delta L S T_{\text {water }}$, right y-axis, blue) of pure water pixels with respect to sensor ZA in Chicago (top) and New York City (bottom). The solid lines indicate the mean values of LST (red) and $\Delta L S T$ (blue) in each $5^{\circ}$ interval of sensor ZA (the $\mathrm{x}$-axis labels the center values of each $\mathrm{ZA}$ interval). The color-shaded bands depict the mean \pm one standard deviation of the distributions. 


\subsubsection{Reducing the bias from sampling due to weather variability}

The ZA variation in each image is relatively small (less than $15^{\circ}$ ) compared to the total possible ZA range of sensor observations (from $-65^{\circ}$ to $\left.+65^{\circ}\right)$. The ZA distribution as a whole is not even, and there are more clearsky data available with the high ZA range (Fig. 2(b) and (c)). Consequently, the $\triangle L S T$ with ZA in each interval sample a range of different hot and cold days. For example, the sampling issue could explain the two strong dips in $\Delta L S T_{\text {water }}$ distribution for Terra-Night satellite overpass of New York in Fig. 3. The daily water temperature variation is relatively small compared to the land surface. Therefore, the impact from daily weather variation on $\Delta L S T$ over land areas is even larger. In order to reduce the potential bias on our quantification of anisotropy from the uneven distribution of hot and cool days across different sensor ZA groups, the ancillary air temperature from a pair of weather stations over the land and adjacent water surface in each city is introduced (see Fig. 1, cross symbols).

Daily weather variation influences LST, as well as the land-water temperature difference $(\Delta L S T)$. Therefore, the value of $\Delta L S T$ described above is not exclusively a function of the sensor angle. High positive correlations have been found between LST and near-surface air temperature $\left(T_{\text {air }}\right)$ under clear skies, but absolute differences exist (Prihodko, 1997; Kawashima et al., 2000; Benali et al., 2012), which are determined by different physical mechanisms that control the two terms. Fortunately (and unlike LST), $T_{\text {air }}$ is independent of the sensor ZA (i.e, there is no anisotropic impact). This makes it 
possible to estimate the effect of weather variability using $T_{a i r}$, and then we could minimize this effect on LST. Since we use the $\Delta L S T$ (land-water difference), accordingly, the air temperature difference $\left(\Delta T_{\text {air }}\right)$ between the land $\left(T_{a i r, l a n d}\right)$ and water surface $\left(T_{a i r, w a t e r}\right)$ is used to subtract this daily weather variation effect from $\Delta L S T$ (Eq. 2), which helps more accurately isolate the impact of anisotropy on LST.

Considering the differences in absolute magnitudes of radiative temperature (measured by the satellites) and air temperature (measured by the weather stations) due to physical mechanisms, as well as in the locations of land and water surface measurements for the two cities, the daily $\Delta T_{\text {air }}$ variation may just account for a proportion of the daily variation of $\Delta L S T$ in these cities. Accordingly, we introduce a term, $\alpha$, to adapt the impact of local weather variation from $\Delta T_{\text {air }}$ on $\Delta L S T$. The new term, $\Delta L S T_{\Delta T_{a i r}}$ in Eq. 3 , is defined by subtracting the anomaly of $\Delta T_{\text {air }}$ from $\Delta L S T$ with a magnitude adjustment $\alpha$ in a time series. The anomaly of $\Delta T_{\text {air }}$ is estimated from $\Delta T_{a i r}-\overline{\Delta T_{a i r}}$, where $\overline{\Delta T_{a i r}}$ is the temporal average of $\Delta T_{\text {air }}$ for the whole time series for each of the four satellite overpasses.

$$
\begin{gathered}
\Delta T_{\text {air }}(t)=T_{\text {air land }}(t)-T_{\text {air }, \text { water }}(t) \\
\Delta L S T_{\Delta T_{\text {air }}}(t)=\Delta L S T(t)-\alpha \times\left(\Delta T_{\text {air }}(t)-\overline{\Delta T_{\text {air }}}\right)
\end{gathered}
$$

where $\mathrm{t}$ is the satellite overpass time.

$\Delta L S T$ and $\Delta T_{\text {air }}$ show a strong positive correlation in the 10-year time 
series for each satellite overpass (when $\alpha$ equals 0 in Eq. 3, as shown in Fig. 4). The correlation between $\Delta L S T_{\Delta T_{a i r}}$ (Eq. 3) and $\Delta T_{a i r}$ (or $\Delta T_{a i r}-\overline{\Delta T_{a i r}}$, where $\overline{\Delta T_{a i r}}$ is a constant for each satellite overpass) are tested with different values of $\alpha$ as shown in Fig. 4. $\alpha$ is determined when $\Delta L S T_{\Delta T_{a i r}}$ (Eq. 3) and $\Delta T_{\text {air }}$ have no significant correlation in a time series. In other words, the variation of air temperature is removed from LST, so the variation of weather conditions will be reduced in $\Delta L S T_{\Delta T_{a i r}}$. Even though the daily variation may be not completely removed, e.g. surface moisture and wind may induce different levels of variation for $\Delta T_{\text {air }}$ and $\Delta L S T$, the later analyses based on $\Delta L S T_{\Delta T_{a i r}}$ are highly aggregated temporally and spatially leading to less impact from daily variation on our results. Accordingly, we set $\alpha$ from $0.8 \sim$ 1.2 for Chicago, and $0.6 \sim 0.8$ for New York City for four satellite overpasses, determined when correlation coefficients are close to 0 (shown in Fig 4). The resulting $\Delta L S T_{\Delta T_{a i r}}$ allows us to identify the anisotropy attributed to the surface properties with minimal influence due to atmospheric effects and uneven sampling of weather conditions at different ZAs.

\subsubsection{Accounting for the effect of urban surface properties}

The angular LST strongly depends on the 3D structures in urban (Voogt, 2008; Lagouarde et al., 2010) and non-urban areas (Lagouarde et al., 2000; Duffour et al., 2015). Particularly in urban areas, radiative transfers, turbulence intensity, and energy exchanges are governed largely by the spatial distribution of buildings, their sizes and orientations (Lagouarde et al., 


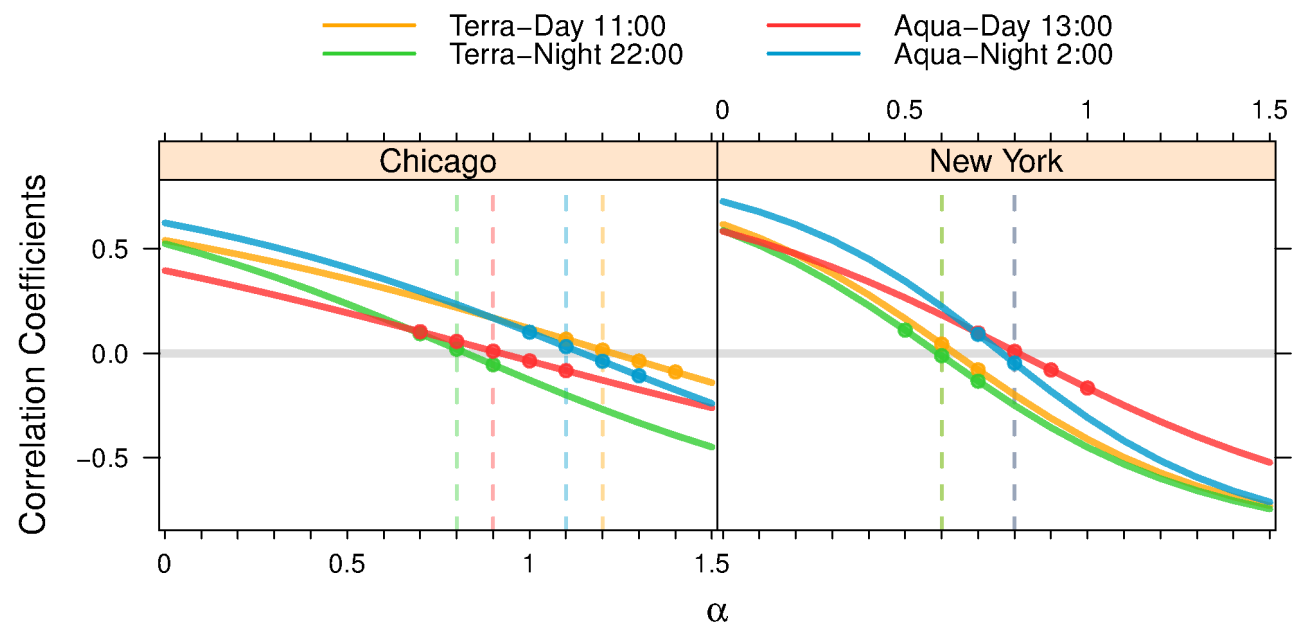

Figure 4: The Pearson product-moment correlation coefficients between spatially averaged $\Delta L S T_{\Delta T_{a i r}}$ and $\Delta T_{\text {air }}$ at different $\alpha$ values. The solid dots indicate where there is no significant correlation at a confidence level of 0.95 . The vertical lines highlight the $\alpha$ value chosen for the temperature correction in Eq. 3. $\alpha$ is set as 1.2, 0.9, 0.8, and 1.1 for Terra-Day, Aqua-Day, Terra-Night, and Aqua-Night in Chicago, respectively; New York has $\alpha$ values of 0.6 for Terra satellite observations and 0.8 for Aqua satellite observations. 
2004; Voogt and Oke, 2003). For example, the Urban Sensor View Model (Voogt, 2008; Krayenhoff and Voogt, 2016) suggests the surface structure is one of most substantial contributors to the anisotropy. The aspect ratio (height-to-width ratio, $\lambda_{s}$ ), complete aspect ratio (complete-to-plan area ratio, $\left.\lambda_{c}\right)$, and roof-to-plan area ratio $\left(\lambda_{p}\right)$ are some of the most widely used urban morphologic parameters in urban atmosphere/climate modeling (Grimmond and Oke, 1999; Hamdi and Schayes, 2008; Voogt, 2008). These are also critical for understanding how shaded and sunlit surfaces affect the anisotropic LST. We calculate these parameters as follows using gridded building footprint and height data for Chicago and New York:

$$
\begin{gathered}
\lambda_{c}=\frac{A_{\text {roof }}+A_{\text {wall }}+A_{\text {ground }}}{A_{\text {plan }}} \\
\lambda_{p}=\frac{A_{\text {roof }}}{A_{\text {plan }}} \\
\lambda_{s}=\frac{1}{2}\left(\frac{\lambda_{c}-1}{1-\lambda_{p}}\right)
\end{gathered}
$$

where $A_{\text {roof }}, A_{\text {wall }}$, and $A_{\text {ground }}$ represent the areas of building roof, wall and exposed ground; $A_{\text {plan }}$ is the total plan area, which is the area of the grid cell. Eq. 6 for the aspect ratio $\left(\lambda_{s}\right)$ is from the estimation algorithm used in the Temperatures of Urban Facets in 3-D (TUF-3D) model by Krayenhoff and Voogt (2007). The buildings are considered to be regularly shaped with flat roofs.

However, we quantified the anisotropic effects of satellite LST within different groups of urban land use fractions of each pixel rather than the building 
morphological indicators directly. The primary reason is that detailed building properties information is not widely available globally or outside of the administrative boundary (such as the building footprint and height information for Chicago and New York), whereas high-resolution land use data are comparably easier to obtain to estimate the urban land use fraction at the MODIS LST resolution. Fig. 5 suggests significantly strong positive relationships between the three urban morphologic indicators and the urban land use fraction, showing the correlation coefficients higher than 0.95. Although the variation tends to be larger when the urban land use fraction increases, and the correlation is nonlinear and varies between the two cities, the general positive correlation is the same for both cities. For this study, which focuses on 10-year averages and aggregates results over space, the use of urban land use fraction to categorize the anisotropic effects on LST into classes is an appropriate proxy of building properties associated with anthropogenic land use intensity.

\subsubsection{Anisotropy indicators and urban heat island curves (UHIC)}

In order to quantify how land use intensity will affect the amplitude of angular LST anisotropy, the effective thermal anisotropy is introduced $\left(\delta L S T_{\text {dir,max-min }}\right.$, Eq. 7, Krayenhoff and Voogt (2007)).

$$
\delta L S T_{\text {dir, } \max -\min }=\max \left(\Delta L S T_{\Delta T_{\text {air }}}(\theta)\right)-\min \left(\Delta L S T_{\Delta T_{a i r}}(\theta)\right)
$$

$\delta L S T_{\text {dir,max-min }}$ captures the maximum temperature difference among 


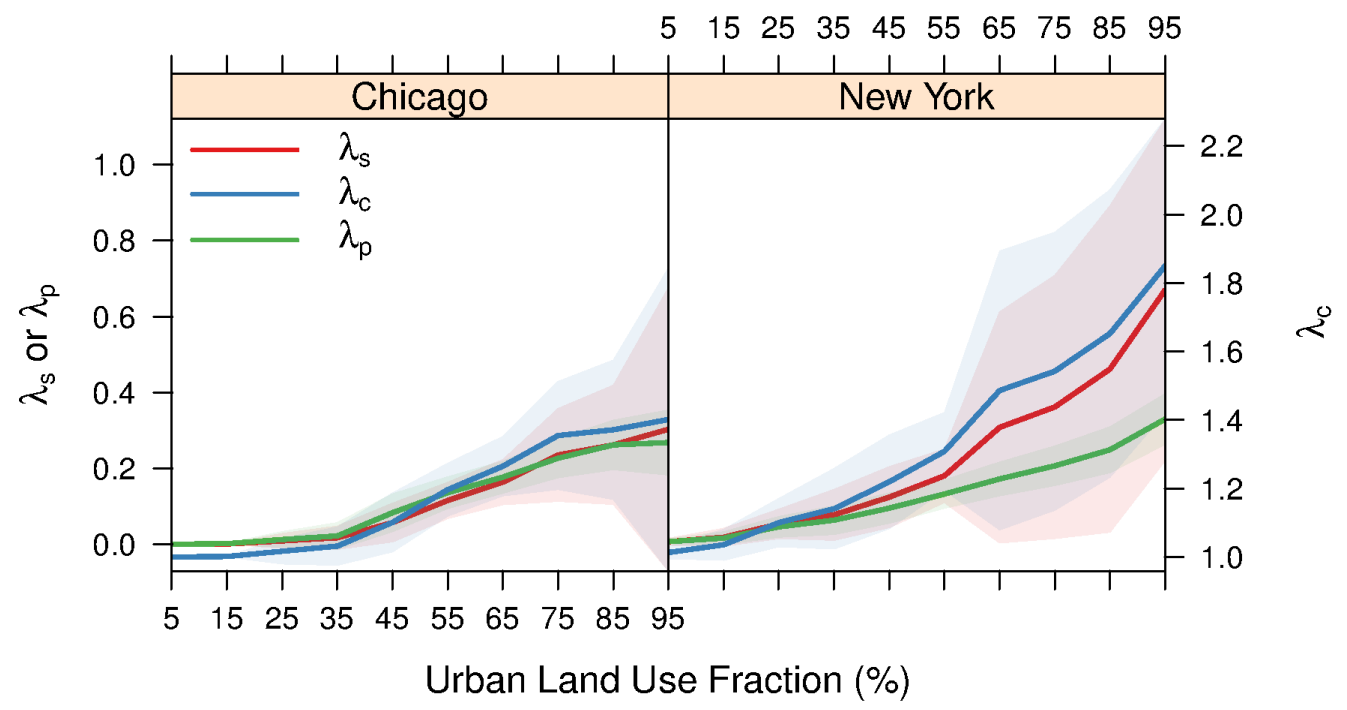

Figure 5: The aspect ratio (height-to-width ratio, $\lambda_{s}$ ), the complete aspect ratio (completeto-plan area ratio, $\left.\lambda_{c}\right)$, and the roof-to-plan area ratio $\left(\lambda_{p}\right)$ versus the urban land use fraction for Chicago and New York. The solid lines represent the mean of each morphologic parameter in every $10 \%$ interval of urban land use fraction (the x-axis indicates the center values of each interval), and the shaded area is one standard deviation from the mean. 
various view angles. In this study, the sensor AA is only available for a predefined direction, so we only consider the anisotropy due to sensor ZA $(\theta)$ variations. LST anisotropic features can be easily compared among cities through this anisotropy indicator, otherwise the absolute $\Delta L S T_{\Delta T_{a i r}}$ values may vary substantially among different cities depending on the selection of water surfaces, e.g. inland reservoirs, large lakes, or rivers.

Furthermore, we employ the urban heat island curve (UHIC) method (Hu and Brunsell, 2015) to assess the impact of anisotropy LST on SUHI intensity quantification. The UHIC utilizes the comprehensive temperature coverage provided by satellite observations, and can depict the temperature variation for different spatial aggregations of gridded land use data. In this study, we chose the urban land use fraction for each $1 \mathrm{~km}$ grid cell as our indicator of anthropogenic land use intensity. The temperatures in different groups of sensor ZAs associated with the urban land use percentages are then categorized within every $5 \%$ interval of urban land use. The maximum SUHI within different SZA groups is calculated for quantifying the impact of anisotropy. More details on the UHIC method can be found in Hu and Brunsell (2015).

\section{Results}

\subsection{Angular effects of LST from MODIS}

After independently processing each LST image by subtracting the mean water LST and adjusting weather variation from $T_{\text {air }}$ accordingly, the entire 
dataset of $\Delta L S T_{\Delta T_{a i r}}$ during 10-year May-September is integrated temporally and categorized into nine urbanization-intensity groups according to urban land use fractions (shown in Fig. 1). Then, the mean value of each group in every $5^{\circ} \mathrm{ZA}$ interval is calculated and the results are shown in Fig. 6. Similar to the findings from Lagouarde et al. (2004, 2012), we observed a strong anisotropy during the daytime, while the nighttime anisotropy is smaller. In order to avoid unrepresentative values due to small sample sizes, Fig. 6 only illustrates the mean temperatures that are statistically meaningful with more than 100 samples. The sensor ZA groups with absolute angles greater than $62.5^{\circ}$ are not included for this reason.

Solar radiation and urban canyon structures are the primary reasons to explain the day/night contrast of anisotropy over urban areas (Lagouarde et al., 2010). The azimuthal angular difference between the solar and sensor positions is typically $45^{\circ} \pm 15^{\circ}$ or $135^{\circ} \mp 15^{\circ}$ (shown in Fig. 2a). Consequently, the daytime anisotropy distributions are more likely asymmetric in Fig. 6 . Two "hot spots" (local maximums) can be clearly observed on the curves for most daytime cases. One occurs likely due to geometric effects when the sensor and solar ZAs are approximately the same (the grey-shaded areas in Fig. 6), especially in the groups with higher urban land use intensities. Although the azimuth viewing directions of sensor and the Sun are not the same in this case, this hot spot likely results from a higher proportion of sunlit surfaces being detected by the sensor. The secondary hot spot occurs mainly during the early afternoon satellite overpass when the sensor ZA is 
near nadir. The sensor detects the largest proportion of streets and roofs when near nadir; these surfaces have higher surface temperatures compared to walls (Voogt and Oke, 1997; Lagouarde et al., 2004; Hamdi and Schayes, 2005; Krayenhoff and Voogt, 2007; Christen et al., 2011). This secondary hot spot has been found in the near-full hemispherical distribution from modeling (Krayenhoff and Voogt, 2016).

Moreover, the daytime anisotropy shares a similar pattern among the nine groups of land use intensity (Fig. 6), governed by solar radiation but with a noticeable difference in amplitude (Fig. 7). It is evident that urban canopy structures exert a strong effect on the LST. The maximum effective directional anisotropy reaches approximately $8.8 \mathrm{~K}$ (Chicago) and $6.5 \mathrm{~K}$ (New York) during afternoon. LST in Chicago has a much higher anisotropy in the most urbanized land use category compared to New York during the afternoon, which is partially due to different urban surface structures and meteorological conditions in the two cities. In the most urbanized group, the more dispersed arrangement of tall buildings in Chicago exhibits larger anisotropy compared to that of the more closely spaced tall building clusters of New York City, in agreement to model results using simple geometries by Krayenhoff and Voogt (2016). Moreover, smaller air temperature differences among different urban land use types due to New York's ocean-influenced climate also help decrease the anisotropy (Voogt, 2008). The role of angular LST over non-urban areas is also important and dependent on land use and associated vegetation canopy structure (Paw U et al., 1989; Li et al., 2004; 
Lagouarde et al., 2000, 2014). For example, there are differences in the amplitude of daytime anisotropy in crop-dominated Chicago rural areas versus forest-dominated New York rural areas.

The nighttime anisotropy is controlled by the heat loss differences due to sky view factors that allow a surface to cool radiatively, as well as the various thermal inertia of urban surface materials, and anthropogenic heat contributions from in-building heating or cooling activities. The nighttime temperature is comparatively symmetric with respect to the sensor ZA. Slightly higher temperatures occur for the largest sensor ZAs, related to the higher proportion of walls that are detected at large view angles. Walls are generally warmer than roofs and streets at night due to differential thermal properties and exposure (Oke et al., 1991; Monaghan et al., 2014; Lagouarde et al., 2012). However, the difference between LSTs for eastward versus westward facing overpasses (due to west-facing walls receiving more afternoon sunlight; e.g., Lagouarde et al. (2012)) is negligible in our results, perhaps because this effect diminishes rapidly after sunset and the evening overpass does not occur until approximately 22:00 local solar time. Comparing the two cities, at nighttime the differences of effective anisotropy among land use intensities largely disappear for Chicago, whereas the anisotropic effects are distinctly higher for urban versus rural land use intensities in New York. This may be related to the higher building density and aspect ratio in New York, which decreases energy loss rates in the urban canyon (Oke, 1982; Svensson, 2004). 


\section{(a) Chicago}

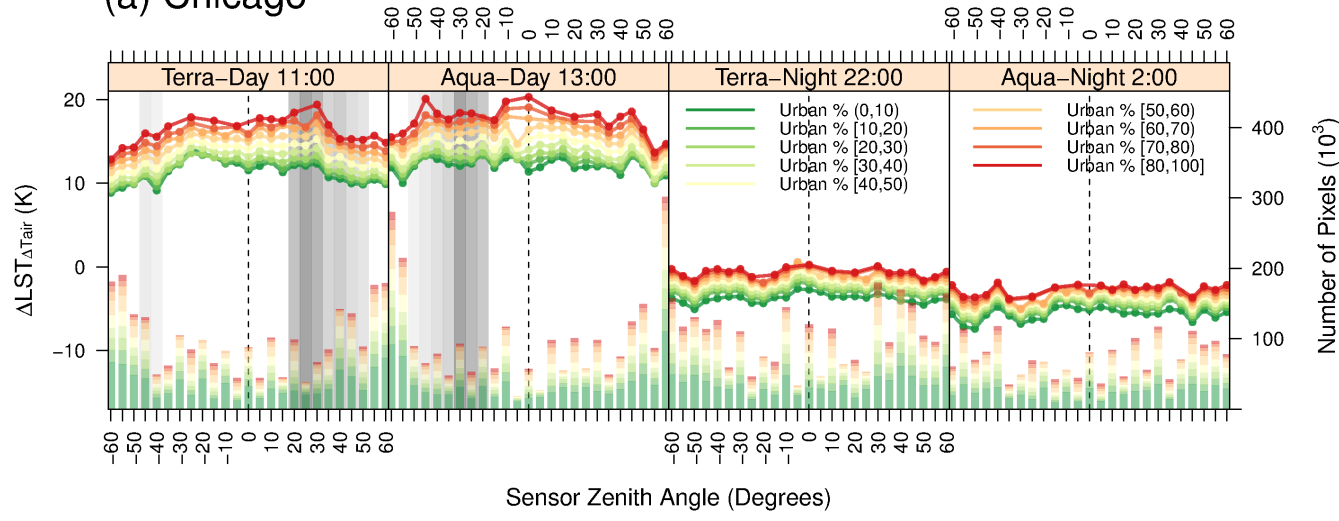

\section{(b) New York}

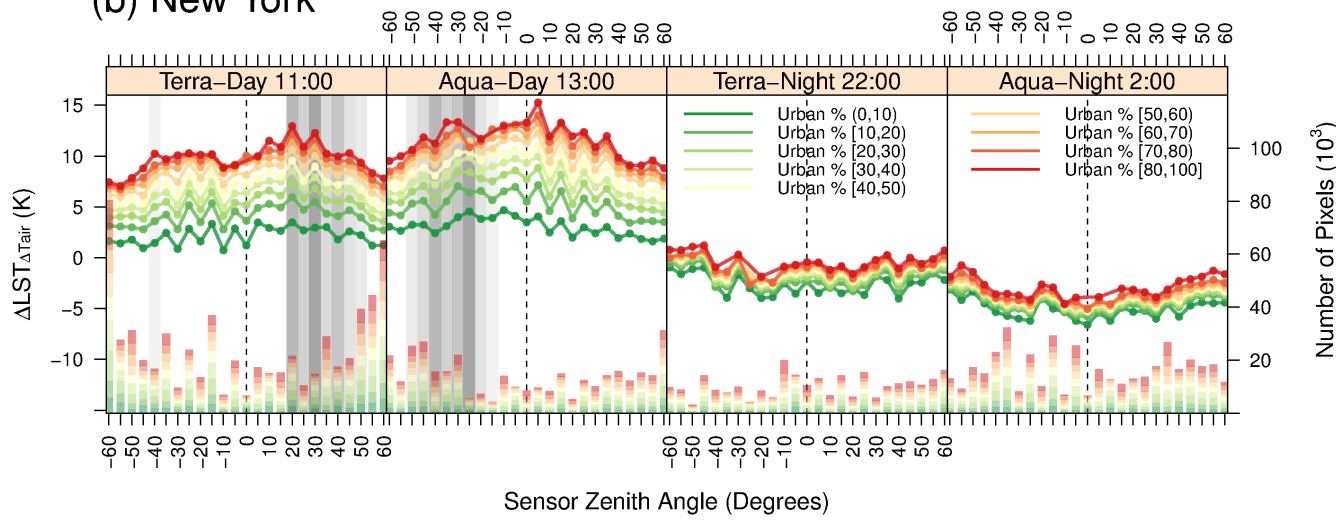

Figure 6: The mean $\Delta L S T_{\Delta T_{a i r}}$ distribution (left-y-axis) versus sensor ZA $(\theta$, x-axis with a $5^{\circ}$ interval) at four satellite overpass times for Chicago (a) and New York City (b). The colored solid lines represent the mean $\Delta L S T_{\Delta T_{a i r}}(\theta)$ grouped into nine urban land use fraction intervals. The corresponding colored bars (right-y-axis) indicate the number of pixels in each urban land use fraction group. The shaded-grey vertical strips show the frequency of solar ZAs from high (darker-grey) to low (lighter-grey). The dashed vertical lines highlight the position of the groups with the smallest sensor ZAs (near the nadir). 


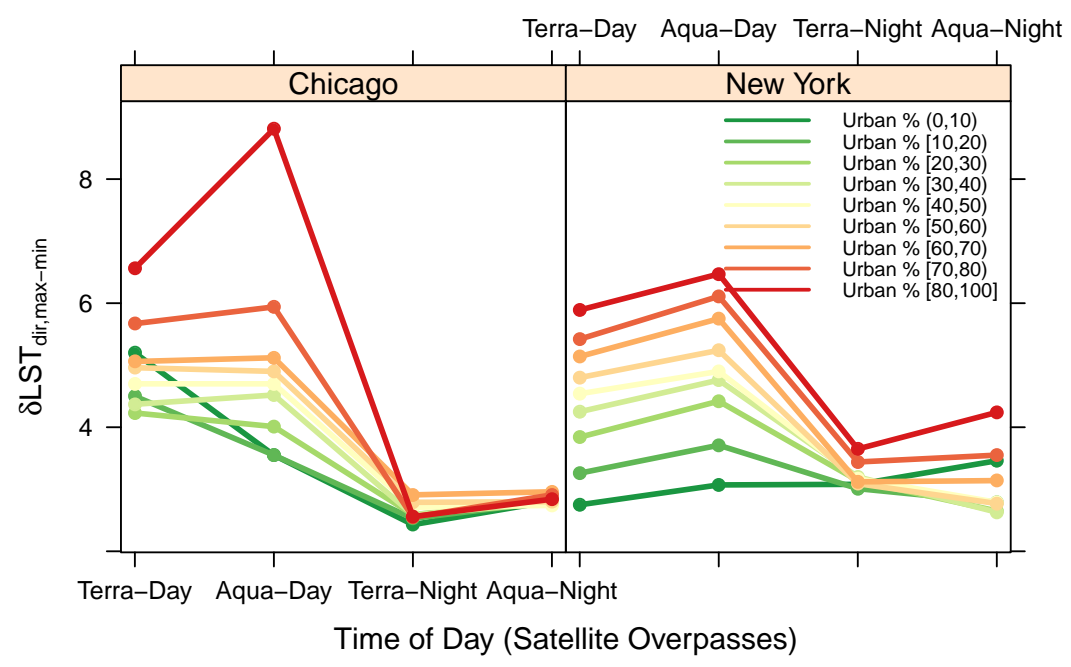

Figure 7: The effective directional anisotropy $\left(\delta L S T_{d i r, \max -\min }\right.$, see Eq. 7$)$ at four satellite overpass times for Chicago and New York, estimated from Fig. 6. The colored solid lines represent $\delta L S T_{d i r, \max -\min }$ grouped by urban land use percentages.

\subsection{Impact of anisotropic LST on SUHI quantification}

The anisotropy of LST becomes critical and potentially problematic when applying satellite-retrieved LST for SUHI studies and other related urban surface process research. In order to assess the influence of anisotropy on the SUHI quantification, the UHIC based on $\Delta L S T_{\Delta T_{a i r}}$ is illustrated in Fig. 8. The temperatures are grouped into six sensor ZA groups ranging from $-65^{\circ}$ to $+65^{\circ}$. An additional group with the sensor ZAs near nadir ([10,10]) is also shown. It is noteworthy that the daytime temperatures in Chicago are slightly lower for the $95 \sim 100 \%$ urban category compared to the $90 \sim 95 \%$ category because the most urbanized areas are situated along the coast of Lake Michigan, where there is a moderating influence from the 


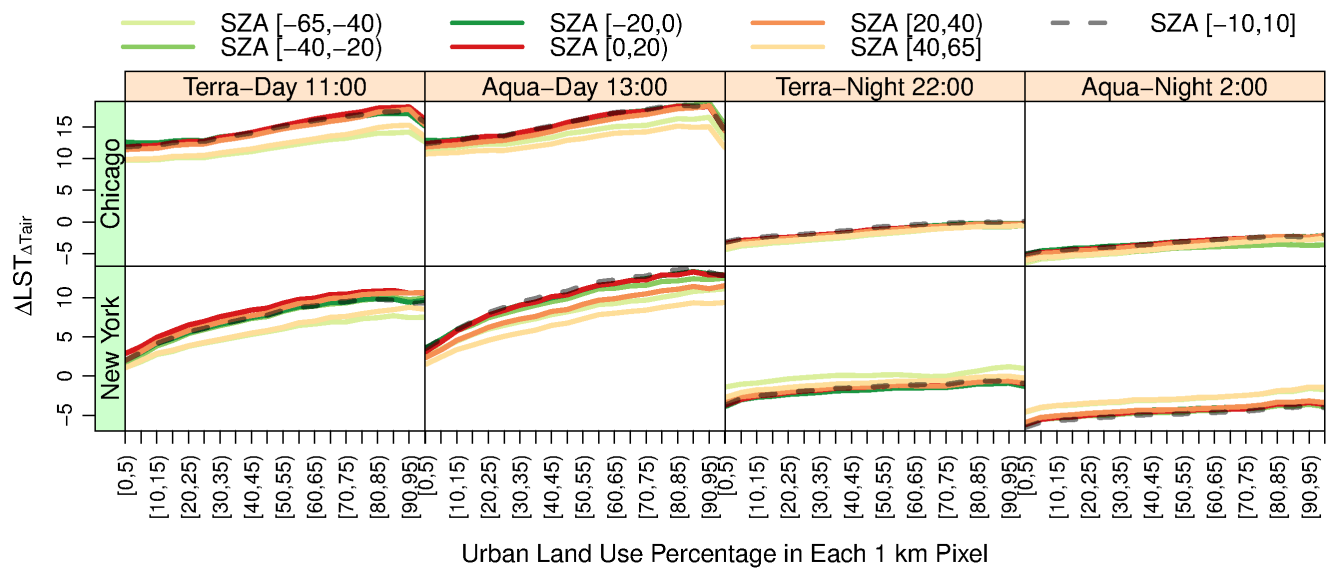

Figure 8: The urban heat island curves (UHICs) estimated from $\Delta L S T_{\Delta T_{a i r}}$ for the four satellite overpass times, categorized by $6+1$ sensor ZA (SZA) groups. The green-colored lines indicate negative ZAs from which the sensor primarily views west-facing objects, whereas the red-colored lines indicate positive ZAs from which the sensor primarily views east-facing objects. The additional group distinguished by dark-grey dashed lines illustrates the temperature distribution observed from near nadir.

water. However, the contrast is not as obvious in New York, possibly because water bodies influence a broader spectrum of land use intensity categories. There are substantial differences among UHICs with various sensor ZAs. The daytime UHICs have higher temperatures for smaller view angles (i.e., nearer to nadir). The objects being viewed during daytime from similar sensor ZAs, but different directions (eastward or westward) differ between morning versus afternoon based on the direction receiving the most sunlight. At nighttime, smaller variations among the UHICs as a function of sensor ZAs are observed, and the results vary by city due to the unique climatic and urban morphology factors of each, as discussed previously.

Fig. 9 presents the maximum SUHI intensity among groups, as estimated 
by the difference between the maximum and minimum temperature on each UHIC from Fig. 8. The highest temperatures occur in highly urbanized regions while the lowest temperatures occur in the most vegetated areas. The results demonstrate that when angular LST is used to quantify the SUHI, an uncertainty of up to $2.3 \mathrm{~K}$ can be introduced from the anisotropy. The daytime variation of SUHI is about $2 \mathrm{~K}$, with little difference between Terra and Aqua overpasses. The nighttime SUHI differences are smaller (about $1 \mathrm{~K}$ in Chicago and $0.4 \mathrm{~K}$ in New York). It is noteworthy that the results in Fig. 9 only demonstrate the anisotropic SUHI magnitude using the UHIC method; for other SUHI indicators (e.g., based on administrative boundaries), the magnitude of the anisotropic influence may differ.

\section{Discussion}

We performed a comprehensive analysis of angular LST from 10-years of MODIS LST data over two large U.S. cities. The study has a number of possible limitations. First, this methodology is applicable only to cities near relatively large and deep water bodies with station observations, which enables calculation of atmospheric attenuation and weather impacts on angular LSTs. For those cities far away from large water bodies, other reference locations that feature isotropic properties that are similar to water surfaces may be used. The atmospheric correction of MODIS LST retrievals is subject to uncertainty, and it may be possible to minimize atmospheric impacts through other methods based on the one presented here. Such methodologies 


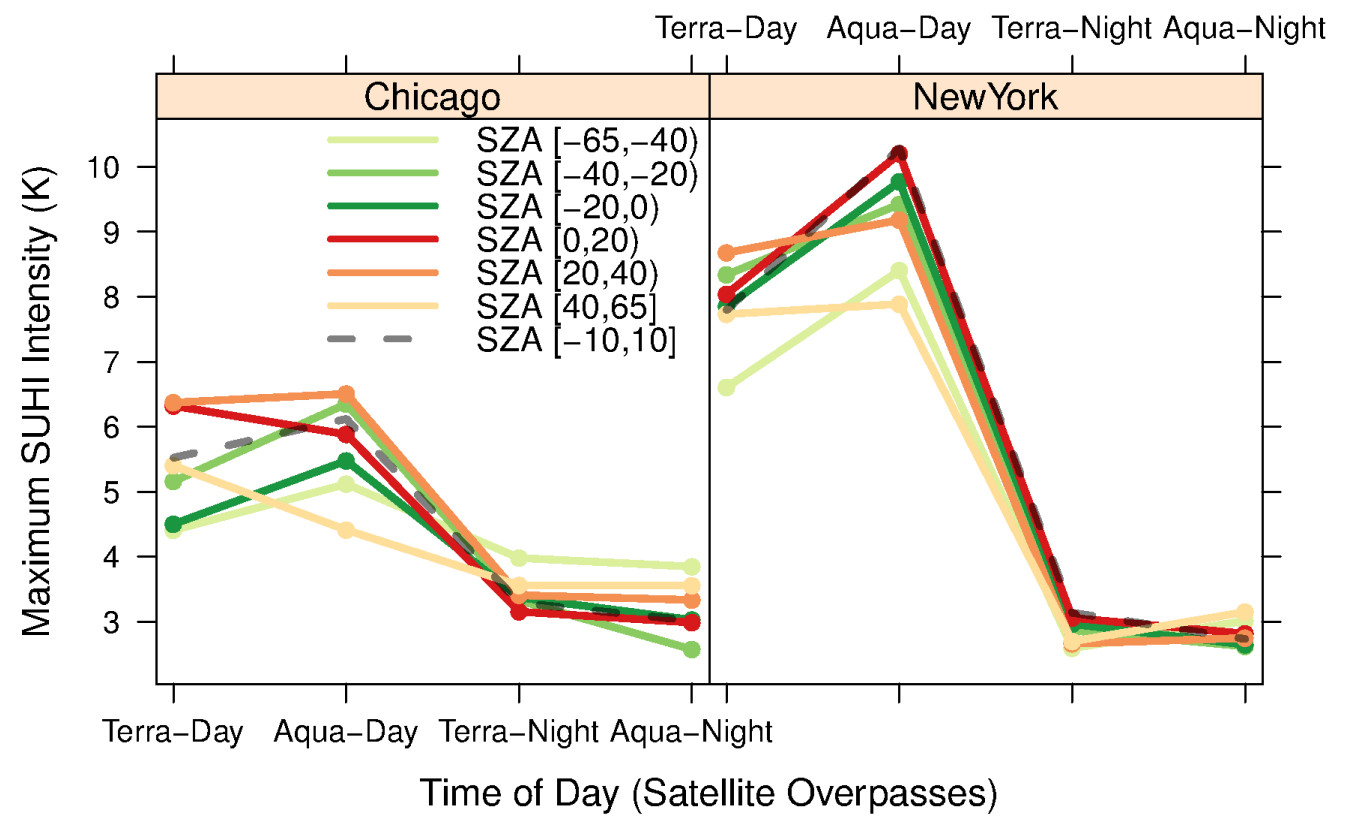

Figure 9: The maximum temperature difference from the UHICs in Fig. 8 for different sensor zenith angles (SZA). 
would require further assessment. Second, the effects of differential angular emissivity on LST are not accounted for. Finally, the analyses is based on the statistical distributions from satellite data aggregated over space and time, therefore it does not address the problem of quantifying the instantaneous thermal anisotropy. Each satellite pixel has unique solar and sensor relative positions at each overpass, and the temperature varies in time, however our results represent the general characteristics of LST anisotropy at the metropolitan scale.

The results are comparable to previous studies based on observations of anisotropy from airborne sensors for both day and night (Lagouarde et al., 2004; Lagouarde and Irvine, 2008; Lagouarde et al., 2010, 2012). Similar to our results, those studies demonstrated that angular LST is highly dependent on urban morphology, including building geometry, road and building orientation, and urban canyon materials and structure (Lagouarde et al., 2004; Voogt and Oke, 2003; Voogt, 2008). Moreover, they showed that the sensor and solar relative positions introduce additional complexity to the angular variation of LST during the daytime, resulting in asymmetric temperature features for different sensor ZAs (Lagouarde et al., 2004; Lagouarde and Irvine, 2008; Lagouarde et al., 2010). For nighttime, we found that summer effective directional anisotropies are about 1-2 K higher than what was observed by Lagouarde et al. (2012). Different seasons (their results were for fall and winter) and diverse urban surface structures of urban areas may contribute to the higher nighttime effects. 
We applied a simplified and integrated indicator, urban land use fraction, to stratify the different intensities of anisotropy according to variations in surface properties. The results suggest that this approach provides a reasonable means to distinguish transitions in morphology between rural, suburban and urban areas within a given city (Fig. 5). While there are other ways to categorize intra-urban land use for climate variability studies (Stewart and Oke, 2012), we employ urban land use fraction because of its simplicity to apply for other cities: high resolution satellite-retrieved land use data is available globally and updated frequently. This is an important consideration because the relationship between urban land use fraction and anisotropy is likely unique for each city, but that's partly because land use isn't the direct driving force for anisotropy, e.g. Krayenhoff and Voogt (2016) showed the linkage of structural parameters to anisotropy.

Angular temperature measurements from MODIS are not "correct" or "incorrect" strictly speaking, because they represent "real" temperatures observed from sensors in different directions. However, the analyses derived from angular LST may cause biased results due to angular effects. While this paper quantifies the impact of anisotropy on LST estimates from MODIS, at this time MODIS LST data cannot be directly adjusted to account for anisotropy due to the highly spatiotemporally aggregated estimate, and further assessment is required for the possible application for this purpose. An accurate adjustment would need to be applied to each pixel of each overpass, to account for the unique anisotropic effects for that pixel. 
It is therefore worth considering how we might be able to reduce the differential (in space and time) impacts of anisotropy. Restricting the sensor view angles within a narrow range (often nadir) is one means to minimize differences in LST due to angular effects, which has a long time in practice (Roth et al., 1989; Hu et al., 2014; Monaghan et al., 2014). Another possible means is by temporally compositing images. Temporally composited LSTs are widely used for large-scale or/and long-term analyses (Clinton and Gong, 2013; Schwarz et al., 2011; Schwarz and Manceur, 2014). Compositing is a practical approach to reduce the impact of missing LST data due to clouds, and it is also a possible way to mitigate differential LST anisotropy. The temporal aggregation does not "cancel" anisotropic features, but the composites provide LST values comprised of a representative sample of various angular effects. This possibly make two or more composite images comparable across time. However, the anisotropic feature is not symmetric at different ZA during the daytime. For example, the "hot-spot" effects will cause different temperatures from opposite directions with similar sensor ZAs. Therefore, the knowledge of anisotropy distribution shape for a given time and surface type as a function of ZA is critical if only a few images are available, because it potentially allows for strategic selection of other view directions to reduce the anisotropy. Another possible compositing approach is to more completely sample the possible ZAs images to construct 'complete' urban surface temperature (Voogt and Oke, 1997) by normalizing the results from the shape of anisotropic distribution for view angles. However, in cloudy 
regions compositing may not be an effective technique for comparing LST from urban and rural pixels across space because heterogeneous cloud distributions necessitate that different images will comprise the membership of rural and urban pixels in the composite image (Hu and Brunsell, 2013).

\section{Conclusions}

Satellite-retrieved LST anisotropy was quantified at a metropolitan scale for Chicago and New York using MODIS LST products during the warm months (May-September) for a 10-year period. We proposed a series of adjustments to satellite-retrieved LSTs in order to isolate the anisotropic features from the possible influences of atmospheric attenuation and daily weather variations. The results demonstrate a strong day/night contrast of thermal anisotropy over cities. The daytime effective thermal anisotropy can reach up to $9 \mathrm{~K}$ for the most urbanized areas, while the nighttime anisotropic effects are weaker but still discernible. These results are in line with other estimates derived from airborne observations and modeling of urban areas. Given the limitation of the satellite overpass time and azimuthal sampling ability from satellite observations, we observed two anisotropic "hot spot" features during daytime: one corresponds to the sensor-sun geometric effect with a higher proportion of sunlit surface components been seen a given view configuration, and the other occurs when sensor zenith angles are near nadir in the afternoon. Differences in anisotropic features between Chicago and New York emphasize the importance of unique urban morphological features 
and local geographical controls on the city climate. Hence, the complexity and uniqueness of urban areas globally requires substantial effort to understand the anisotropy of LST for given regions. This study is the first of its kind to directly evaluate the influence of anisotropy on satellite-based SUHI measurements, demonstrating that anisotropic effects can modify the SUHI as measured with MODIS LST by $2.3 \mathrm{~K}$, which is about $25-50 \%$ of the total magnitude of the SUHI depending on the season and macro-climate setting of the city (Imhoff et al., 2010; Clinton and Gong, 2013).

In the future we hope to address some methodological limitations of this work by exploring the use of indicators other than urban land use fraction to distinguish anisotropy, by accounting for emissivity effects on LST, and by modifying our methodology and extending it application to non-coastal cities. In addition to methodological limitations, our results face many uncertainties linked to aggregating the results in space and time. We need to validate our estimates of anisotropic variability with airborne observations or other satellite data. Sensor-view models can simulate anisotropic features at finer time scales, and simultaneously map the anisotropy for all zenith and azimuth angles within a hemispheric field of view, which is a possible tool for the anisotropy adjustment for LST products in the future. However, current modeling techniques face a number of challenges, such as unavailability of facet temperatures (Voogt, 2008), unrepresentative canyon structures (Voogt, 2008; Lagouarde and Irvine, 2008; Lagouarde et al., 2010, 2012), poorly understood vegetation effects (Krayenhoff and Voogt, 2007; 
Voogt, 2008), the uncertainty of emissivity (Voogt, 2008), and the impact of regional and mesoscale weather variations (Krayenhoff and Voogt, 2007). Combining our methodology with modeling approaches may be a promising solution for future anisotropy studies. The ultimate goal is to develop a practical model that is able to adjust temperature from off-nadir to nadir, or vice versa, which will be able to extend the application of satellite-retrieved angular LST to urban areas globally.

\section{Acknowledgments}

The National Center for Atmospheric Research is sponsored by the National Science Foundation. The authors would like to thank NASA for providing MODIS LST products freely, and to thank the reviewers for their valuable comments to improve the manuscript.

\section{References}

\section{References}

Benali, a., Carvalho, a. C., Nunes, J. P., Carvalhais, N., Santos, A., 2012. Estimating air surface temperature in Portugal using MODIS LST data. Remote Sensing of Environment 124, 108-121.

Christen, A., Meier, F., Scherer, D., 2011. High-frequency fluctuations of surface temperatures in an urban environment. Theoretical and Applied Climatology 108 (1-2), 301-324. 
Clinton, N., Gong, P., 2013. MODIS detected surface urban heat islands and sinks: Global locations and controls. Remote Sensing of Environment 134, $294-304$.

Cuenca, J., Sobrino, J. A., 2004. Experimental measurements for studying angular and spectral variation of thermal infrared emissivity. Applied Optics $43(23), 4598$.

Duffour, C., Olioso, A., Demarty, J., Van der Tol, C., Lagouarde, J.-P., 2015. An evaluation of SCOPE: A tool to simulate the directional anisotropy of satellite-measured surface temperatures. Remote Sensing of Environment $158,362-375$.

Dyce, D., 2014. A sensor view model to investigate the influence of tree crowns on effective urban thermal anisotropy. Master's thesis, The University of Western Ontario.

Grimmond, C. S. B., Oke, T. R., 1999. Aerodynamic properties of urban areas derived from analysis of surface form. Journal of Applied Meteorology $38(9), 1262-1292$.

Hamdi, R., Schayes, G., 2005. Validation of the Martilli's urban boundary layer scheme with measurements from two mid-latitude European cities.

Hamdi, R., Schayes, G., 2008. Sensitivity study of the urban heat island intensity to urban characteristics. International Journal of Climatology $28(7), 973-982$. 
Homer, C. H., Fry, J. A., Barnes, C. A., 2012. The national land cover database, U.S. Geological Survey fact sheet 2012-3020. Tech. rep.

Hu, L., Brunsell, N. A., 2013. The impact of temporal aggregation of land surface temperature data for surface urban heat island (SUHI) monitoring. Remote Sensing of Environment 134, 162-174.

Hu, L., Brunsell, N. A., 2015. A new perspective to assess the urban heat island through remotely sensed atmospheric profiles. Remote Sensing of Environment 158, 393-406.

Hu, L., Brunsell, N. A., Monaghan, A. J., Barlage, M., Wilhelmi, O. V., 2014. How can we use MODIS land surface temperature to validate long-term urban model simulations? Journal of Geophysical Research: Atmospheres 119 (6), 3185-3201.

Hung, T., Uchihama, D., Ochi, S., Yasuoka, Y., Tran, H., 2006. Assessment with satellite data of the urban heat island effects in Asian mega cities. International Journal of Applied Earth Observation and Geoinformation $8(1), 34-48$.

Imhoff, M. L., Zhang, P., Wolfe, R. E., Bounoua, L., 2010. Remote sensing of the urban heat island effect across biomes in the continental USA. Remote Sensing of Environment 114, 504-513.

Kawashima, S., Ishida, T., Minomura, M., Miwa, T., 2000. Relations between 
surface temperature and air temperature on a local scale during winter nights. Journal of Applied Meteorology 39, 1570-1579.

Kimes, D., 1980. Effects of vegetation canopy structure on remotely sensed canopy temperatures. Remote Sensing of Environment 10 (3), 165-174.

Kottek, M., Grieser, J., Beck, C., Rudolf, B., Rubel, F., 2006. World map of the Köppen-Geiger climate classification updated. Meteorologische Zeitschrift 15 (3), 259-263.

Krayenhoff, E., Voogt, J., jan 2016. Daytime thermal anisotropy of urban neighbourhoods: Morphological causation. Remote Sensing 8 (2), 108.

Krayenhoff, E. S., Voogt, J. A., 2007. A microscale three-dimensional urban energy balance model for studying surface temperatures. Boundary-Layer Meteorology 123 (3), 433-461.

Lagouarde, J.-P., Ballans, H., Moreau, P., Guyon, D., Coraboeuf, D., 2000. Experimental study of brightness surface temperature angular variations of Maritime Pine (Pinus pinaster) stands. Remote Sensing of Environment $72(1), 17-34$.

Lagouarde, J.-P., Dayau, S., Moreau, P., Guyon, D., 2014. Directional anisotropy of brightness surface temperature over vineyards: Case study over the Medoc Region (SW France). IEEE Geoscience and Remote Sensing Letters 11 (2), 574-578. 
Lagouarde, J.-P., Hénon, A., Irvine, M., Voogt, J., Pigeon, G., Moreau, P., Masson, V., Mestayer, P., 2012. Experimental characterization and modelling of the nighttime directional anisotropy of thermal infrared measurements over an urban area: Case study of Toulouse (France). Remote Sensing of Environment 117, 19-33.

Lagouarde, J.-P., Hénon, A., Kurz, B., Moreau, P., Irvine, M., Voogt, J., Mestayer, P., 2010. Modelling daytime thermal infrared directional anisotropy over Toulouse city centre. Remote Sensing of Environment $114(1), 87-105$.

Lagouarde, J.-P., Irvine, M., 2008. Directional anisotropy in thermal infrared measurements over Toulouse city centre during the CAPITOUL measurement campaigns: first results. Meteorology and Atmospheric Physics $102(3-4), 173-185$.

Lagouarde, J.-P., Moreau, P., Irvine, M., Bonnefond, J.-M., Voogt, J. A., Solliec, F., 2004. Airborne experimental measurements of the angular variations in surface temperature over urban areas: Case study of Marseille (France). Remote Sensing of Environment 93 (4), 443-462.

Li, D., Bou-Zeid, E., 2013. Synergistic interactions between urban heat islands and heat waves: The impact in cities is larger than the sum of its parts. Journal of Applied Meteorology and Climatology 52 (9), 2051-2064.

Li, Z.-L., Tang, B.-H., Wu, H., Ren, H., Yan, G., Wan, Z., Trigo, I. F., 
Sobrino, J. A., 2013. Satellite-derived land surface temperature: Current status and perspectives. Remote Sensing of Environment 131, 14-37.

Li, Z.-L., Zhang, R., Sun, X., Su, H., Tang, X., Zhu, Z., Sobrino, J. A., 2004. Experimental system for the study of the directional thermal emission of natural surfaces. International Journal of Remote Sensing 25 (1), 195-204.

Monaghan, A. J., Hu, L., Brunsell, N. A., Barlage, M., Wilhelmi, O. V., 2014. Evaluating the impact of urban morphology configurations on the accuracy of urban canopy model temperature simulations with MODIS. Journal of Geophysical Research: Atmospheres 119 (11), 6376-6392.

Niclòs, R., Caselles, V., Coll, C., Valor, E., Rubio, E., 2004. Autonomous measurements of sea surface temperature using in situ thermal infrared data. Journal of Atmospheric and Oceanic Technology 21 (4), 683-692.

Niclòs, R., Valor, E., Caselles, V., Coll, C., Sánchez, J. M., 2005. In situ angular measurements of thermal infrared sea surface emissivity-validation of models. Remote Sensing of Environment 94 (1), 83-93.

Oke, T. R., 1982. The energetic basis of the urban heat island. Quarterly Journal of the Royal Meteorological Society 108, 1-24.

Oke, T. R., Johnson, G. T., Steyn, D. G., Watson, I. D., 1991. Simulation of surface urban heat islands under 'ideal' conditions at night Part 2: Diagnosis of causation. Boundary-Layer Meteorology 56 (4), 339-358. 
Paw U, K. T., Ustin, S. L., Zhang, C.-A., 1989. Anisotropy of thermal infrared exitance in sunflower canopies. Agricultural and Forest Meteorology 48 (1-2), 45-58.

Pinheiro, A., Privette, J., Mahoney, R., Tucker, C., 2004. Directional effects in a daily AVHRR land surface temperature dataset over Africa. IEEE Transactions on Geoscience and Remote Sensing 42 (9), 1941-1954.

Prihodko, L., 1997. Estimation of air temperature from remotely sensed surface observations. Remote Sensing of Environment 60 (3), 335-346.

Ren, H., Yan, G., Liu, R., Li, Z.-L., Qin, Q., Nerry, F., Liu, Q., 2015. Determination of optimum viewing angles for the angular normalization of land surface temperature over vegetated surface. Sensors (Basel, Switzerland) 15 (4), 7537-70.

Rigo, G., Parlow, E., 2007. Modelling the ground heat flux of an urban area using remote sensing data. Theoretical and Applied Climatology 90 (3-4), 185-199.

Roth, M., Oke, T. R., Emery, W. J., 1989. Satellite-derived urban heat islands from three coastal cities and the utilization of such data in urban climatology. International Journal of Remote Sensing 10 (11), 1699-1720.

Schwarz, N., Lautenbach, S., Seppelt, R., 2011. Exploring indicators for quantifying surface urban heat islands of European cities with MODIS 
land surface temperatures. Remote Sensing of Environment 115 (12), 31753186.

Schwarz, N., Manceur, A. M., 2014. Analyzing the influence of urban forms on surface urban heat islands in Europe. Journal of Urban Planning and Development, A4014003.

Snyder, W. C., Wan, Z., Zhang, Y., Feng, Y.-Z., 1998. Classification-based emissivity for land surface temperature measurement from space. International Journal of Remote Sensing 19 (14), 2753-2774.

Sobrino, J. A., Cuenca, J., 1999. Angular variation of thermal infrared emissivity for some natural surfaces from experimental measurements. Applied Optics 38 (18), 3931-3936.

Stewart, I. D., Oke, T. R., 2012. Local climate zones for urban temperature studies. Bulletin of the American Meteorological Society 93 (12), 18791900.

Svensson, M. K., 2004. Sky view factor analysis - implications for urban air temperature differences. Meteorological Applications 11 (3), 201-211.

U.S. Census Bureau Population Division, 2014. Annual estimates of the resident population: April 1, 2010 to july 1, 2014. http://factfinder.census.gov/faces/tableservices/jsf/pages/productview.xhtml?src

Voogt, J., 2008. Assessment of an urban sensor view model for thermal anisotropy. Remote Sensing of Environment 112 (2), 482-495. 
Voogt, J. A., Grimmond, C. S. B., 2000. Modeling surface sensible heat flux using surface radiative temperatures in a simple urban area. Journal of Applied Meteorology 39 (10), 1679-1699.

Voogt, J. A., Oke, T. R., 1997. Complete urban surface temperatures. Journal of Applied Meteorology 36 (9), 1117-1132.

Voogt, J. A., Oke, T. R., 2003. Thermal remote sensing of urban climates. Remote Sensing of Environment 86 (3), 370-384.

Wan, Z., 2007. MODIS land surface temperature products users' guide. Tech. rep.

Wan, Z. M., Dozier, J., 1996. A generalized split-window algorithm for retrieving land-surface temperature from space. Ieee Transactions on Geoscience and Remote Sensing 34 (4), 892-905.

Weng, Q., Hu, X., Quattrochi, D. A., Liu, H., 2014. Assessing intra-urban surface energy fluxes using remotely sensed ASTER imagery and routine meteorological data: A case study in Indianapolis, U.S.A. IEEE Journal of Selected Topics in Applied Earth Observations and Remote Sensing 7 (10), 4046-4057.

Weng, Q., Lu, D., Schubring, J., 2004. Estimation of land surface temperature-vegetation abundance relationship for urban heat island studies. Remote Sensing of Environment 89 (4), 467-483. 
${ }_{813}$ Zhang, D., Tang, R., Tang, B., Wu, H., Li, Z., 2015. A simple method for soil 814 moisture determination from LST-VI feature space using nonlinear inter815 polation based on thermal infrared remotely sensed data. IEEE Journal of 816 Selected Topics in Applied Earth Observations and Remote Sensing 8 (2), $817 \quad 638-648$. 